difficult problem for the Trust. Applications are now being received from students whose parents or guardians in the earlier years of its history would not have had recourse to the Trust, and each application presents a case in itself. Moreover, since individual education authorities frequently withdraw the bursary for a further year if the student fails to pass all his degree examinations at the appropriate time, the student often applies to the Trust for assistance towards his class fees, and the whole circumstances attendant on failure must be reviewed. While, for the time being, the executive committee has awarded class fees when there seemed to be a reasonable prospect of the student's being able to reinstate himself, it shares with the education authorities considerable anxiety as to the total effect of these bursary regulations emanating from the Education (Scotland) Act, 1946. The 1,301 students assisted during 1952-53 received $£ 20,003$ compared with $£ 15,069$ to 1,026 students during 1951-52; repayments by former beneficiaries were $£ 2,062$ from 34 beneficiaries, compared with $£ 1,985$ during 1951-52.

The amount devoted to the research scheme during 1952-53 was $£ 32,646$, or some $£ 5,000$ less than during 1951-52, and scholarship awards were made more rigorously. The special fund for assisting the publication of work embodying original research now stands at $£ 9,059$. Both the scheme recently introduced to give opportunity for senior members of university staffs to go abroad for periods of research up to one year, and the block grants to the four universities to enable members of their staff to use their vacations fruitfully in research, whether at home or on the Continent of Europe, are regarded as successful. Grants were also made to Scottish learned societies, to "A Dictionary of the Older Scottish Tongue", "The Scottish National Dictionary", "The Scottish Historical Review", and, through the universities, to "The Third Statistical Account". Appended to the report are lists of publications by fellows, scholars and recipients of grants received since September 1952, of recipients of grants and of assisted papers, and a résumé of reports upon the work of investigators under the research scheme.

In the mathematical, physical and engineering section, Sir Richard Southwell comments particularly on Dr. W. Paul's work on the effect of high pressures on the properties of semiconductors; Dr. A. G. Mackie's work on the hodograph method for the problem of compressible flow around sharp corners, and Mr. P. B. MacFarlane's study of Pleistocene changes of sea-level. In medicine, I. A. Macpherson has made marked progress in studying hæmagglutination by viruses and its inhibition by bacterial polysaccharides, and J. Grieve on the treatment of experimental peritonitis in rats with phthalylsulphathiazole.

In chemistry, Dr. T. R. R. McDonald's work on the crystal structure of ammonium bifluoride promises to yield valuable information about the nature of the hydrogen bond. Dr. A. R. M. Gibb has made excellent progress in synthesizing tropolone derivatives in his work on the preparation of compounds, structurally related to colchicine, which might possess its antimitotic effects but not its poisonous properties ; Miss Evelyn E. B. Smith has discovered several new reactions involving uridine pyrophosphate derivatives and her investigation of the enzymic mechanisms concerned has now gained her a Beit fellowship for medical research to study enzymic mechanisms at the University of Glasgow. Other investigations in chemistry noted in the advisers' report are those of W. J. Bremner on the flow of gases through a porous plug; A. J. Sorrie on the synthesis of benzisotropolone, in which he has discovered the effectiveness as a condensing agent of a fused mixture of sodium chloride and aluminium chloride; R. Logan on the use of radioactive phosphorus to find the rates at which phosphorus is taken up into the different nucleotides in the constituents of the cytoplasm of the liver cells in the domestic fowl; and G. A. J. Goodlad on the enzymes found in the liver which effect transformations of sugar phosphates.

In biology, Dr. J. W. H. Lawson has commenced a lengthy investigation on the systematies and biology of aquatic species of the Chironomids, G. D. Scott is investigating the ecology and physiology of lichens, Miss Janet E. O. Towers has studied the chromosomes in amphibian oocytes, D. C. W. Smith has done much work on the endocrine control of osmoregulation in Salmonids and E. A. Salzen has made a good beginning in a study of the rate of growth of insect embryos at different stages of development.

\section{AVERAGES OF BRIGHT SUNSHINE AND TEMPERATURE FOR GREAT BRITAIN AND NORTHERN IRELAND}

$T$

HE Meteorological Office has recently published two pamphlets giving, respectively, averages of sunshine and of temperature for Great Britain and Northern Ireland during the period 1921-50*. The sunshine measurements are all made by the Campbell-Stokes instrument, which does not record sunshine below a certain level of intensity, so that the averages refer to 'bright' sunshine. The pamphlet gives average annual and monthly totals and daily means for the months and the year for 187 stations distributed all over Great Britain and Northern Ireland. The records show that, on the average, the Isle of Wight and the Sussex coast are the sunniest areas, with an annual average of more than five hours a day. This area is sunniest in summer as well as in winter. The least sunny rural areas are north and mountainous distriets of Scotland, in which some stations average a little less than three hours a day. Sandown had most sunshine in the period with an annual average of $1,840 \mathrm{hr}$., but was very closely followed by Worthing, Ventnor and Eastbourne. The publication contains useful material for the study of the loss of sunshine in the centre of great cities. It is noteworthy that Bunhill Row in the City of London averaged $3 \cdot 45 \mathrm{hr}$. a day against the $4 \mathrm{hr}$. of Kew and Hampstead, and Manchester (Whitworth Park) $2 \cdot 9 \mathrm{hr}$. against $4 \cdot 1 \mathrm{hr}$. at Hoylake and Southport. The loss of sunshine in cities is greatest, both absolutely and relatively, in winter. The publication includes a table comparing the averages for 1901-30, 1906-35 and 1921-50 at seven well-distributed stations. The mean daily sunshine at Birmingham, $3.56 \mathrm{hr}$., was the same in 1921-50 as 1901-30, but the other stations show reductions of up to $0.09 \mathrm{hr}$.

* Air Ministry : Meteorological Office. Averages of Temperature for Great Britain and Northern Ireland, 1921-50 (M.O. 571); pp. ii +36 ; 2s. Averages of Bright Sunshine for Great Britain and Northern Ireland, 1921-50 (M.O. 572) ; pp. ii +32; 2s. (London :
H.M.S.O., 1953.) 
The pamphlet on temperature contains monthly and annual averages of maximum, minimum and mean, half (maximum plus minimum), temperatures in degrees Fahrenheit. The lowest annual average temperature recorded, $43 \cdot 5^{\circ}$ at Braemar $(1,111 \mathrm{ft}$.$) , is$ 9 deg. below the highest, $52 \cdot 5^{\circ}$ at Scilly. The mean July maximum ranges from $73.4^{\circ}$ in London to $57 \cdot 8^{\circ}$ at Lerwick. In January Cornwall has the highest maxima, with means of $48-50^{\circ}$, but over most of England and Scotland mean maxima are between 42 and $45^{\circ}$. It is necessary to go to stations at heights of more than $500 \mathrm{ft}$. to find mean January maxima below $40^{\circ}$ (Braemar $39.4^{\circ}$ ) or mean January minima below freezing point (Balmoral $28 \cdot 4^{\circ}$ ). Comparisons between the monthly and annual averages for the periods 1901-30, 1906-35 and 1921-50 are given for seven stations. At all the stations there was an increase in mean annual temperature of about 0.5 deg. from the first to the third period. The increase, at about 1 deg., was most marked in summer. Spring and autumn also were slightly warmer; but winter was slightly colder. It is particularly interesting that the difference between the mean annual temperature of the two periods should be so uniform over the whole country.

\section{CORPUSCULAR ECLIPSE IN THE $F_{2}$-LAYER AND ITS ASSOCIATION WITH SOLAR FLARES AND $M$-REGIONS}

\author{
By Dr. PRABHAT K. SEN GUPTA \\ Meteorological Office, Safdarjung Airport, New Delhi \\ and \\ S. N. MITRA \\ Research Department, All India Radio, New Delhi
}

$\mathrm{T}$ $\mathrm{HE}$ fact that certain intense magnetic storms tend to occur about a day after the visual observation of eruptions (flares) on the sun has led to the belief that these storms are caused by the arrival of fast beams of corpuscles (which taken as a whole are neutral) from the sun having velocities of the order of $1,000-2,000 \mathrm{~km}$./sec. The most direct evidence of the presence of fast incoming particles has been provided by the observations of Meinel ${ }^{1}$ during an intense auroral display on August 18-20, 1950. By pointing his spectrograph towards the magnetic zenith and comparing the result with that obtained with the spectrograph towards the magnetic horizon, he found that the $H \alpha$ line had a violet shift ( $\lambda$ 7I A. for the wing and $\lambda 10 \mathrm{~A}$. for the maximum) which corresponded to a velocity of $3,200 \mathrm{~km} . / \mathrm{sec}$. for the incoming protons.

In the ionospheric regions the effect of the solar flares is manifested in the form of Dellinger type of fade-outs, which synchronize with the time of the flares, indicating that it is the ultra-violet light emitted from the solar flare which is responsible for the effect. S. N. Mitra and Mazumdar ${ }^{2}$ found from an analysis of Delhi records for the years 1946-49 that a number of the flares were followed $20-40 \mathrm{hr}$. later by further fade-outs. For example, out of thirteen flares of type 3 and $3+$, four were accompanied by simultaneous fade-outs, and in three cases, fade-outs occurred $20-40 \mathrm{hr}$. later. The other six flares were not, however, attended by simultaneous or later fade-outs. During the same period, twentythree flares of type 2 had been reported, and they found one of these flares to be associated with simultaneous fade-out; in two cases the fade-outs were delayed by $20 \sim 40 \mathrm{hr}$. and the rest of the flares were apparently ineffective in causing fade-out.

The delayed fade-outs which are found to set in about one or two days after the visual observation of a solar flare may be attributed to the action of fast neutral beams of corpuscles originating from the flares, and speeding towards the earth with velocities of the order of $1,600-800 \mathrm{~km}$./sec. Chapman ${ }^{3}$ pointed out that if a portion of the ionization in the ionospheric layers is caused by the impact of a solar corpuscular stream, an effect should be observable during solar eclipse. He showed that a corpuscular eclipse should occur about two hours earlier than the optical eclipse if the velocity of the corpuscles is taken to be $1,600 \mathrm{~km}$./sec. Later, Chapman ${ }^{4}$ gave reasons why the ideal conditions for the corpuscular effect to be recorded are not likely to be present every time. We wish to point out that there are a number of eclipse observations on record where the investigators have directed attention to the presence of a corpuscular eclipse in accordance with Chapman's ideas: for example, those of October 1, 1940, at Queenstown by Pierce ${ }^{5}$; January 25, 1944, at Huancayo by Ledig et al. ${ }^{6}$; February 25 , 1952, at Delhi by S. N. Mitra?, and on the same occasion at Banaras by S. S. Banerjee et al. ${ }^{8}$. In Fig. 1, a few examples have been reproduced with the values of $f_{0} F_{2}{ }_{2}^{2}$ prepared from the observations, plotted against L.M.T. A corpuscular effect is clearly seen in Figs.

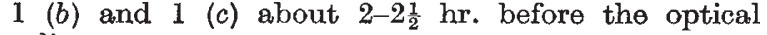
eclipse.

\section{Source of Corpuscular Streams}

The presence of the corpuscular eclipse about two hours before the optical eclipse provides evidence that fast corpuscles are coming with velocities of the order of $1,600 \mathrm{~km}$. $/ \mathrm{sec}$.; but it does not indicate whether these corpuscles are associated with solar flares or other disturbed regions of the sun. Judging from the high percentage of magnetic storms and simultaneous radio fade-outs which do not seem to be associated with any observed flare at all, it appears that there may be some other agency on the sun which emits the corpuscles in question, for S. N. Mitra and Mazumdar ${ }^{2}$ found that out of 122 fade-outs recorded during the years 1946-49 at Delhi, $81 \cdot 2$ per cent apparently had no connexion with any flare at all. This encourages us to link up the corpuscular radio fade-outs with $M$-region activity.

It is well known that some of the moderate magnetic storms which seem to have no connexion with visible solar flares have a tendency to recur every 27 days with the synodic rotation of the sun. These magnetic storms, also known as $M$-storms, have been attributed by Bartels ${ }^{\theta}$ to unidentified active regions of the sun which he calls $M$-regions. The physical nature of the $M$-regions has not yet been established with certainty, nor have the $M$-regions been yet clearly associated with any prominent physical feature on the sun. Waldmeier ${ }^{10}$ originated the idea that the intensity of the $C$-regions, that is, the coronal regions of bright line emission (particularly $\lambda$ 5303), could be used as an index of the activity of $M$-regions. The analysis of Shapley and Roberts ${ }^{11}$ for the years 1942-44 during a period of sunspot minimum indicated that the appearance of 